\title{
Mechanical Properties of Lightweight Concrete Using Recycled Cement-Sand Brick as Coarse Aggregates Replacement
}

\author{
Ilya Joohari ${ }^{1, *}$, Nor Farhani Ishak $^{1}$, and Norliyati Mohd Amin ${ }^{2}$ \\ ${ }^{1}$ School of Environmental Engineering, Universiti Malaysia Perlis, 02600 Arau, Perlis, Malaysia \\ ${ }^{2}$ Faculty of Civil Engineering, Universiti Teknologi MARA, 40450 Shah Alam Selangor, Malaysia
}

\begin{abstract}
This paper presents the result of replacing natural course aggregate with recycled cement-sand brick (CSB) towards the mechanical properties of concrete. Natural aggregates were used in this study as a control sample to compare with recycled coarse aggregates. This study was also carried to determine the optimum proportion of coarse aggregates replacement to produce lightweight concrete. Besides, this study was conducted to observe the crack and its behaviour development during the mechanical testing. Through this study, four types of concrete mixed were prepared, which were the control sample, $25 \%, 50 \%$ and $75 \%$ replacement of CSB. The test conducted to determine the effectiveness of recycled CSB as coarse aggregates replacement in this study were slump test, density measurement, compression test, and flexural test and. The strength of concrete was tested at 7 days and 28 days of curing. From the results obtained, the optimum proportion which produced the highest strength is $25 \%$ replacement of recycled CSB. The compressive and flexural strength has decreased by $10 \%-12 \%$ and $4 \%-34 \%$ respectively compared to the control sample. The presence of recycled coarse aggregates in sample has decreased the density of concrete by $0.8 \%-3 \%$ compared to the control sample.
\end{abstract}

\section{Introduction}

One of the significant problems nowadays is the accumulation and unsatisfactory management of construction and demolition waste. Therefore, it is increasing along with continuous spreading of industrialization and urbanization. However, it was stated that the construction and demolition waste can be recycled and reused as a raw material for new applications [1]. Usually, most of the waste materials are left behind at landfill or illegally dumped. In addition, the environmental impact can be reduced by making more sustainable use of this waste.

Waste management is one of the priorities of every community [2]. As a result, it has become an evident that good waste management can enhance better quality of life. The main principle of a quality waste management is by reducing the mass production of new

\footnotetext{
* Corresponding author: ilya@unimap.edu.my
} 
waste, then find the way to recycled and reuse an existing waste, and safe and ecologically acceptable in depositing of unused waste.

Nowadays, research on lightweight aggregates has been conducted worldwide in a large range. The structural lightweight concrete has their own advantages such as superior heat, sound insulation characteristics due to air voids and lower coefficient of thermal expansion [3]. Moreover, the reduction in dead weight in concrete will reduce the cross section of structural members and steel reinforcement.

\subsection{Problem Statement}

Natural resources of this country are decreasing year by year. In this research, the natural coarse aggregates that will be used are gravel. Gravel is found naturally, mostly in lake, river, and ocean beds, where the constant movement of the water and waves keeps the gravel from settling and fusing with other rocks, sand is a form of micro-gravel, being tiny stones worn down by constant motion. Gravel deposits are mined and sifted to create commercial gravel products, which are used in many industrial applications as well as construction. To prevent the natural resources from decreasing, one of the ways is to recycle and reuse the waste materials such as the cement-sand brick that produced in construction site. Therefore, in order to prevent the natural coarse aggregates from depleting, the recycled brick will be used as a replacement.

The environment impact can be reduced also by making more sustainable use of this waste material. This research is conducted to investigate the effect of replacing the coarse aggregates with recycled cement-sand brick. By determining the optimum proportion of coarse aggregates replacement, this will not only determine the lightweight concrete, it also can determine which proportion will produce both lightweight and have the strength of a normal concrete.

\section{Materials and Methodology}

\subsection{Materials}

The materials used in this research are recycled CSB as a replacement of coarse aggregates. There are two types of mould used in this research such as cube and prism mould. The size of cube mould is $100 \mathrm{~mm} \times 100 \mathrm{~mm} \times 100 \mathrm{~mm}$ while the prism mould is $100 \mathrm{~mm} \times 100$ $\mathrm{mm} \times 500 \mathrm{~mm}$. Besides, the replacement of recycled CSB at $25 \%, 50 \%$ and $75 \%$ and the result is compared with the control sample without recycled CSB replacement. Table 1 below shows the concrete design mix for the respective concreting work.

Table 1. Concrete Mix Design.

\begin{tabular}{|c|c|}
\hline Type of Mix & $\mathbf{~ k g / \mathbf { m } ^ { \mathbf { 3 } }}$ \\
\hline Free water content & 190.00 \\
\hline Modified free/water cement ratio & 351.85 \\
\hline Fine aggregates content & 534.28 \\
\hline Coarse aggregates content & 1373.87 \\
\hline
\end{tabular}




\subsection{Methodology}

Recycled Cement-Sand Brick (CSB) is the main material in this research. Firstly, the wastes were collected at Jejawi, Kangar. After collecting the waste material, the preparation of waste material is conducted. The preparations of waste material consist of crushing process, which consists of manual crushing process with the use of a hammer in order to obtain the desired size.

Before the mixing process, aggregates have undergone a sieving process. This method is called sieve analysis. It is a test that classified the aggregates to different sizes. For this research, the sizes of aggregates were between $10 \mathrm{~mm}$ to $14 \mathrm{~mm}$. Through this test, course aggregate and fine aggregates was collected. By using recycled CSB as coarse aggregates replacement, it is expected to reduce the density of concrete. In this research, the grade of concrete designed was Grade 25. The maximum free-water/cement ratio for this design is 0.54 .

After all the preparation for materials has completed, concreting the cubes and prism were conducted according to the design mix. Slump test was conducted at fresh state in order to determine the workability of the concrete mix. After 24 hours, the specimens were cured in water for a period of 7 and 28 days prior to mechanical testing. The testing involves compressive strength and flexural strength test to determine the mechanical behaviour of the concrete.

\section{Results and Discussions}

\subsection{Slump Test}

Slump test was the first test conducted on this research, with the design for slump to be in between $10-30 \mathrm{~mm}$. It was carried out to study the effect of replacement of CSB on the workability. There are no slight different in slump for all proportion including control sample except for the $25 \%$ coarse aggregate replacement. The result shows that the consistency in grade of concrete is stiff. Density test was also conducted for this research. It was carried out to determine whether the concrete was in lightweight category or not. The optimum proportion to produce lightweight concrete is $75 \%$ of replacement of recycled $\mathrm{CSB}$. The result shows that the density of concrete kept decreasing between the ranges of $0.8 \%$ to $3 \%$ from control sample. This is because the density of recycled CSB is 2070 $\mathrm{kg} / \mathrm{m}^{3}$ while the density of gravel is $2700 \mathrm{~kg} / \mathrm{m}^{3}$, which is why the density keeps decreasing when the substitution of recycled CSB is increasing.

Based on a previous research conducted, the density of recycled brick is lower about $8 \%$ to $17 \%$ than the ordinary sample [4]. The increasing of substitution of natural aggregates with crushed brick will cause the percentage of entrained air increases. It is because of a lower density of brick aggregates, concrete made with it should have lower density than the one with natural aggregates in concrete. The results for slump test are shown in Table 2. 
Table 2. Result for Slump.

\begin{tabular}{|c|c|}
\hline Samples & Slump (mm) \\
\hline Control & 22 \\
\hline $25 \%$ Coarse Aggregate Replacement & 18 \\
\hline $50 \%$ Coarse Aggregate Replacement & 20 \\
\hline $75 \%$ Coarse Aggregate Replacement & 20 \\
\hline
\end{tabular}

\subsection{Compressive and Flexural Test}

These tests were carried out to study the effect of replacement of CSB on mechanical and physical properties of the concrete in term of strength development. The concrete was designed to be Grade 25. The result of compression test shows that the strength of concrete is decreasing by $10 \%$ to $14 \%$ from the control sample while the result of flexural test shows that the strength of concrete is decreasing by $5 \%$ to $35 \%$ from the control sample. The optimum proportion that has produced the highest compressive and flexural strength is $25 \%$ of replacement of CSB. The strength keeps decreasing because the percentage of substitution of recycled CSB is increasing, which is related to the lower density of CSB which is $2070 \mathrm{~kg} / \mathrm{m}^{3}$. The proportion of $25 \%$ replacement gives the highest strength among the three proportions because the percentage of gravel inside the concrete is $75 \%$. The strength of concrete with $100 \%$ of gravel (control sample) is higher compare to the strength with $75 \%$ of gravel. As the percentage of proportion of replacement of recycled CSB increases, the strength for compression and flexural decreasing. The results of compressive and flexural strength are shown in Table 3.

Table 3. Result for Compressive and Flexural Strength Test.

\begin{tabular}{|c|c|c|c|}
\hline \multirow{2}{*}{ Samples } & \multicolumn{2}{|c|}{ Compressive Strength, MPa } & $\begin{array}{c}\text { Flexural Strength, } \\
\text { MPa }\end{array}$ \\
\cline { 2 - 4 } & & & $\mathbf{2 8}$ Days \\
\cline { 2 - 4 } & $\mathbf{7}$ Days & $\mathbf{2 8}$ Days & 1.436 \\
\hline Control & 17.903 & 25.593 & 1.336 \\
\hline 25\% Coarse Aggregate Replacement & 18.648 & 21.895 & 0.873 \\
\hline 50\% Coarse Aggregate Replacement & 13.501 & 19.671 & 0.835 \\
\hline 75\% Coarse Aggregate Replacement & 13.257 & 17.448 & \\
\hline
\end{tabular}

These both compression and flexural test result have been approved by previous researcher. It was said that after 28 days of curing process, the compressive strength is decreasing in range $10 \%$ to $35 \%$ for recycled coarse aggregates [4] in comparison with an ordinary concrete while according to another study [5], it was stated that the flexural strength of the concrete with crushed brick is about $8 \%$ to $15 \%$ lower than the one of the ordinary concrete. There have a correlation between flexural and compressive strength of concrete with recycled brick aggregates. The decreasing in flexural strength has a similar pattern with compressive strength [4]. 


\subsection{Crack Behaviour}

After compression and flexural test are conducted, the crack behaviour on the concrete is observed. This test is conducted to observe the crack and its behaviour. In this research, all the samples were tested after curing process for 7 and 28 days. The Fig. 1 shows the crack behaviour on the cube concrete after compression test. The concrete with $25 \%$ proportion of replacement of recycled CSB shows a cracking starts at the left and right of the concrete at the same time. The crack produced a double line from top to bottom of the concrete. The cracking pattern for $25 \%$ replacement is quite the same with concrete of $50 \%$ replacement. The cracking for $50 \%$ replacement starts at the left of the concrete that produced a single line from bottom to top. Lastly, the concrete with $75 \%$ proportion of replacement shows a cracking start at the left of the concrete. The crack produced a single line same as the concrete with $50 \%$ replacement but small cracking produced at the top of the concrete.
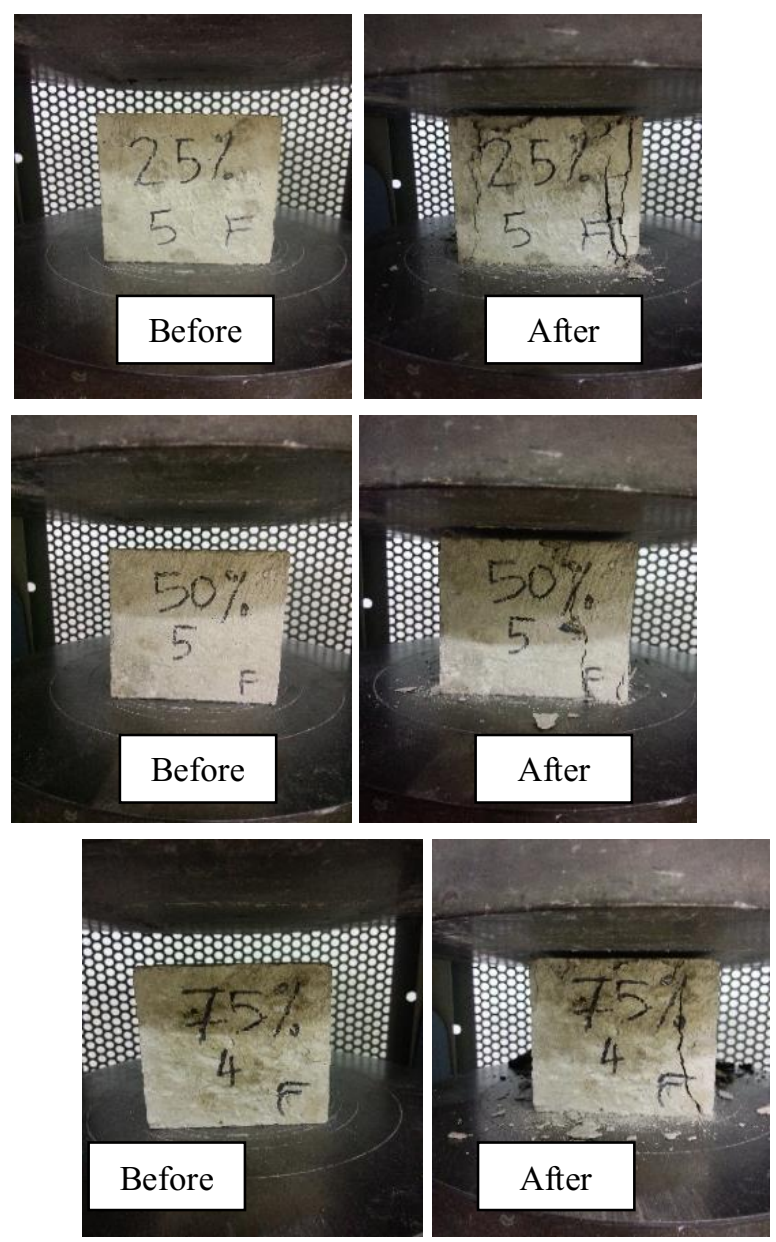

Fig. 1. The crack behaviour before and after compression test for all proportion.

Fig. 2 shows the crack behaviour on the prism concrete after flexural test. All proportion of replacement of recycled CSB shows a crack with single line at the middle of the 
concrete. The crack starts from bottom to top. For the proportion of $50 \%$ and $75 \%$ of replacement, the crack split producing micro cracks at the bottom of the prism. There are different lengths of crack line for every percentage of proportion. The length of crack line for $25 \%, 50 \%$ and $75 \%$ are $90 \mathrm{~mm}, 95 \mathrm{~mm}$ and $50 \mathrm{~mm}$ respectively.

All crack pattern and behaviour are related with density, compression and flexural test. The least amount of cracks was produced on concrete is $25 \%$ replacement of recycled CSB. It is because the density of the concrete for this proportion is greater than the other two proportions by $0.8 \%$ to $2.5 \%$. Besides, the percentage of gravel inside the concrete of this proportion is $75 \%$ higher compare to another two proportion that will make the concrete is stronger to cater the load. In the same way, the compressive and flexural strength for this proportion is the strongest among the other three proportions by $10 \%$ to $12 \%$ and $4 \%$ to $8 \%$ respectively. The other two proportions indicate the sample failed with a deep crack and then separated into two halves. When the density, compressive and flexural strength increases, the crack produce on the sample is less.
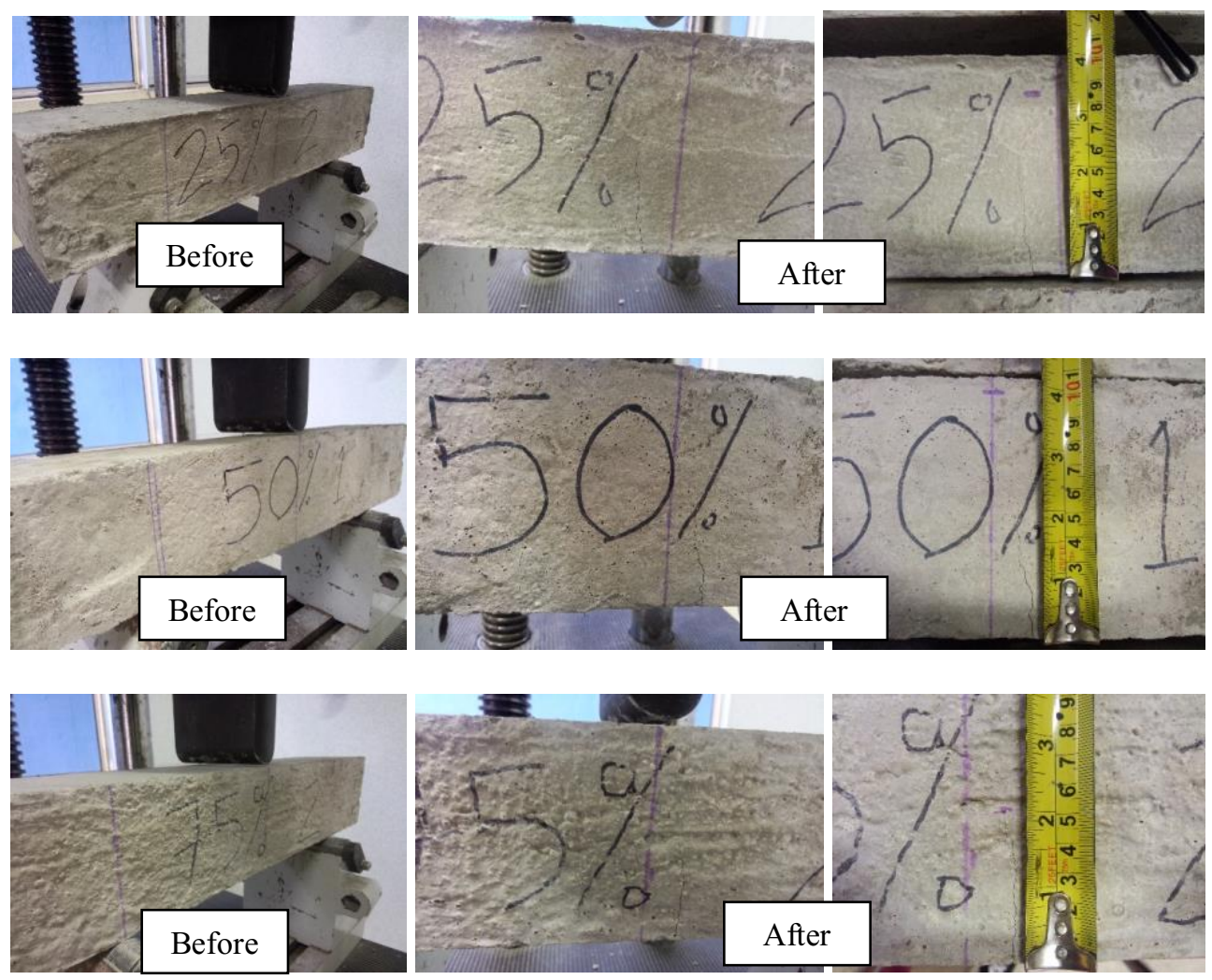

Fig. 2. The crack behaviour before and after flexural test for all proportion.

\section{Conclusions}

1. The $25 \%$ of replacement of recycled CSB gives an optimum effect on the physical and mechanical properties of concrete. The compressive strength of the concrete is decreasing by $10 \%$ to $12 \%$ when compare with control sample. The flexural strength is decreasing by $4 \%$ to $34 \%$ as the number of proportion increasing. The higher the 
percentage of replacement of recycled CSB, the lower the compressive and flexural strength of the concrete.

2. The optimum proportion of coarse aggregates replacement in terms of producing lightweight concrete is $75 \%$ of replacement of CSB. It is because the density of CSB is $2070 \mathrm{~kg} / \mathrm{m}^{3}$ while the density of gravel is $2700 \mathrm{~kg} / \mathrm{m}^{3}$. It can be concluded that, the density of the concrete is decreasing by $0.8 \%$ to $3 \%$ from control sample. Even though the density of concrete is decreasing, but the density achieved is higher than required for lightweight concrete.

3. The fewest cracking produce on concrete for both prism and cube concrete is $25 \%$ of replacement of CSB. With the small cracking produce, it shows that the concrete is in high density, compressive and flexural strength too. It is because the percentage of gravel in this proportion is higher which was $75 \%$ replacement.

This study was conducted with the technical support from the Structural Lab at the School of Environmental Engineering, and with the financial support from Universiti Malaysia Perlis.

\section{References}

1. Batayneh, M.; Marie, I.; Asi, I., Use of Selected Waste Materials In Concrete Mixes, Waste Management 2, 1870-1876 (2007)

2. Bjegovic, D., Sustainability as a Condition for Development in Croatia, Proceedings of International Conference on Sustainability in the Cement and Concrete Industry. Lillehammerpp. 2-16, (2007)

3. K. M. A Hossain, Blended Cement and Lightweight Concrete Using Scoria: Mix Design, Strength, Durability and Heat Insulation Characteristics, Ryerson University Toronto, Ontario, Canada, (2006).

4. Debied, F., Kenai, S., The Use Of Concrete And Crushed Bricks As Aggregate In Concrete, Construction and Building Materials 22, 886-893 (2008)

5. Khalaf, F. M.; DeVenny, A. S., Recycling of Demolished; Masonry Rubble as Coarse Aggregate in Concrete: Review, Journal of Materials in Civil Engineering 16, 331-340 (2004) 